\title{
Lung volume reduction for severe emphysema: do we need a scalpel
}

\section{or a scope?}

\author{
D. Van Raemdonck* and V. Ninane
}

ABSTRACT: Resectional lung volume reduction has proven to be superior to medical treatment in reducing dyspnoea and in increasing lung function, survival and quality of life in a very well selected, low risk group of hyperinflated patients with heterogeneous emphysema predominantly in the upper lobe. Nevertheless, this intervention is hampered by an important pulmonary (30\%) and cardiovascular (20\%) morbidity, mainly as a result of prolonged ( $>7$ days) air leak, and a $5 \%$ risk of death as a result of the surgical intervention.

Results from ongoing randomised trials are awaited in order to determine whether less invasive, non-resectional lung volume treatment of emphysema via the bronchoscope using endobronchial valves, airway bypass stents or biological adhesives/heated water vapour will yield similar improvement with less morbidity and reduced mortality, compared with surgical resection. Furthermore, it is hoped that endoscopic lung volume reduction techniques may help patients with homogeneous emphysema currently excluded by most teams for the resectional procedure.

\section{KEYWORDS: Bronchoscopy, emphysema, hyperinflation, surgery, volume reduction}

hronic obstructive pulmonary disease (COPD) is a growing problem worldwide causing disabling symptoms of dyspnoea and limited exercise tolerance, and can lead to early death [1]. The risk of death from any cause can be predicted by a score based on body-mass index, airflow obstruction, dyspnoea and exercise capacity (BODE index) [2].

The major mechanisms that explain airflow limitation are airway narrowing due to airway abnormalities (e.g. increased smooth muscle airway tone and remodelling) and decreased elastic recoil associated with emphysematous destruction of the lung. As a result of this latter mechanism, the diseased lung requires less pressure than a normal lung to inflate and, once inflated, exerts less pressure to empty, leading to an increased total lung capacity and residual volume. Lungs in an emphysematous patient, therefore, tend to remain inflated with overexpansion of the thoracic cage and flattening of the diaphragm. Patients are trapped in a permanent state of hyperinflation. The harder the patient strains to breathe, the more the airways collapse and obstruct the outflow of gas, leading to dynamic hyperinflation and increased breathlessness.
The mainstay of treatment has been the use of a variety of inhaled bronchodilators, anti-inflammatory medications including corticosteroids and antioxidants, oxygen supplementation and, in some patients, a comprehensive pulmonary rehabilitation programme. The most frequently prescribed medications, namely inhaled bronchodilators and anti-inflammatory drugs, act primarily on the airway component of COPD and medical therapy still remains poorly effective in the condition of severe emphysema, when the main mechanism of airflow limitation is the loss of elastic recoil of the lung.

A variety of surgical approaches to improving symptoms and restoring function of patients with emphysema and COPD refractory to medical treatment have been described [3]. Early results of surgery were often encouraging but surgery rarely achieved sustained objective functional improvement and most of those procedures were gradually abandoned. Of all the early surgical interventions, the only two survivors are bullectomy and the modern form of lung volume reduction surgery (LVRS). Lung transplantation was added in the 1980s as a valuable treatment option in well-selected candidates. Each surgical

\section{AFFILIATIONS}

*Dept of Thoracic Surgery, University Hospital Gasthuisberg, Leuven, and \# Dept of Pneumology, St Pierre Hospital, Brussels, Belgium.

CORRESPONDENCE

D. Van Raemdonck

Dept of Thoracic Surgery

University Hospital Gasthuisberg

Herestraat 49

B-3000 Leuven

Belgium

E-mail: dirk.vanraemdonck@

uzleuven.be

Received:

May 262010

Accepted:

May 272010

\section{PROVENANCE}

Publication of this peer-reviewed article was supported by

GlaxoSmithKline, Belgium (principal sponsor, European Respiratory Review issue 117). 
procedure serves a unique physiological entity, ideal selection criteria and specific expected outcomes.

Bronchoscopic techniques aiming at lung volume reduction or expiratory flow improvement are procedures that are still under investigation. It is hoped that functional improvement can be obtained to the same magnitude seen with surgical volume reduction, but with a less invasive technique.

The indications and the techniques for both surgical and bronchoscopic lung volume reduction, and the results seen thereafter, are discussed.

\section{SURGICAL LUNG VOLUME REDUCTION}

Resectional surgery for diffuse emphysema was first reported $>40$ yrs ago by BRANTIGAN and co-workers [4, 5]. Although subjective improvement was documented in $75 \%$ of the surviving patients, they presented no objective data in the form of physiological measurement. The procedure never gained widespread acceptance until it was reintroduced in 1995 by COOPER et al. [6]. This group reported favourable results in 16 patients who underwent bilateral LVRS via median sternotomy with resection of $20-30 \%$ of each lung. Patients experienced marked improvements in forced expiratory volume in $1 \mathrm{~s}$ (FEV1) (+82\%) and forced vital capacity (FVC) $(+27 \%)$ as well as improvements in oxygen levels, 6-min walk distance and quality of life. These results were updated to include more patients (150 in 1996 [7] and 250 in 2003 [8]). Prolonged air leak was the most common complication $(45.2 \%)$. The in-hospital mortality was $<5 \%$ and survivals were $93.6 \%, 84.4 \%$, and $67.7 \%$ at 1,3 and 5 yrs, respectively. There was a significant improvement in FEV1 and residual volume $(\mathrm{RV})$ that lasted $\geqslant 5$ yrs [8].

Several uncontrolled studies by other groups in the USA reported improvement in lung function, gas exchange and exercise capacity after bilateral LVRS. Three single institutional studies compared LVRS to pulmonary rehabilitation [9-11], concluding that LVRS improved FEV1, exercise capacity and quality of life.

By reducing the size of the lungs and thus total lung capacity, the circumferential pull on the small airways is restored, and the RV is decreased and FEV1 is increased. The flattening of the diaphragm is reduced, thereby restoring its excursion during breathing. Hyperinflation of the lung with cardiac compression is reduced, thereby improving haemodynamics.

Three surgical approaches have been reported to achieve this goal: 1) a midline sternotomy with stapled resection of lung tissue; 2) video-assisted thoracoscopy (VATS) with stapled resection or folding of lung tissue; and 3) VATS with laser ablation. The latter operation has been abandoned at this time because of inferior results and complications. Resection is accomplished by placing a stapling device on the most affected emphysematous zones until the desired amount of tissue (20$30 \%$ ) is resected. The most destroyed areas of the lung are identified preoperatively by high-resolution computed tomography (CT) scan and quantitative ventilation/perfusion scanning. Median sternotomy and VATS are comparable in terms of morbidity and mortality, and functional results. VATS, however, allows earlier recovery at a lower cost [12]. Both unilateral and bilateral LVRS yield significant improvement but bilateral LVRS seems to be superior with regard to spirometry, lung volumes and quality of life [13]. Other investigators, however, have reported opposite conclusions [14]. As no results from randomised studies are available, this remains, therefore, an area of controversy. Unilateral LVRS is usually accepted for patients with marked unilateral emphysematous changes or in certain patients in whom bilateral LVRS is contraindicated [15, 16]. Whether a unilateral or bilateral VATS is performed will depend ultimately on personal surgeon and centre preference. The resection can be accomplished bilaterally in one procedure or staged over time when lung function deteriorates again $[17,18]$. Patients with severe emphysema and resectable lung cancer who have a favourable anatomy for lung volume reduction surgery may undergo a combined cancer resection and lung volume reduction surgery with an acceptable risk and good long-term survival [19].

Following publications by the group at Barnes Hospital [6, 7] on the favourable results with LVRS on lung function, exercise capacity and quality of life, many centres in the USA offered this treatment option to their emphysema patients, sometimes resulting in a significant mortality as a result of poor candidate selection. A large randomised controlled trial of LVRS versus medical therapy, known as the National Emphysema Treatment Trial (NETT), was undertaken in 1,218 patients to assess the efficacy of this surgical procedure, the duration of benefit and the related morbidity and mortality [20]. In the first report by the NETT research group, a group of patients (fig. 1) was identified with a high risk of early mortality following the LVRS procedure (FEV1 $<20 \%$ and diffusing capacity of the lung for carbon monoxide (DL,CO) $<20 \%$ or homogeneous emphysema on CT scan) [21]. These patients should be excluded from this procedure and assessed for lung transplantation if there are no other medical contraindications (table 1). A second study identified four groups of patients who had a different risk of mortality and likelihood of improving quality of life and exercise capacity: those with upper-lobe versus non-upper-lobe distribution of emphysema and low versus high cardiopulmonary exercise capacity after completing pulmonary rehabilitation [22]. Patients with predominantly upper-lobe emphysema and low exercise capacity showed significantly improved long-term survival following LVRS compared with medically treated patients. Conversely, patients with predominantly non-upper-lobe emphysema and high exercise capacity had poorer long-term survival following surgery compared with medically treated patients (fig. 1). In the remaining two subgroups, long-term survival was no different between both treatment arms. A further analysis by the NETT research group [23] showed that the effects of LVRS were durable, with improved exercise capacity throughout a 3yr period and fewer symptoms throughout a 4-yr period in all patients with upper lobe disease who were treated surgically. The NETT further showed that LVRS can be performed in selected patients with acceptable mortality (5.5\%) but significant cardiovascular (20\%) morbidity (infarction, pulmonary embolus and arrythmia) and pulmonary (nearly 30\%) morbidity (tracheostomy, failure to wean, reintubation and pneumonia), with non-upper-lobe-predominant emphysema, low DL,CO, and low FEV1 as negative predictors [24]. Furthermore, air leak accompanies LVRS in $90 \%$ of the patients and is 
often prolonged and associated with a more complicated and protracted hospital course [25].

In most studies on LVRS, patients who showed no heterogeneity in destruction of the emphysematous lungs on CT scan were excluded from surgery or experienced small benefits only. Recently, the Zurich group reported that selected patients with so-called homogeneous type emphysema can also undergo LVRS successfully with low perioperative mortality, and significant improvement in dyspnoea, lung function and exercise capacity, which is maintained for several years [26].
LVRS will have an impact on the number of patients that are ultimately transplanted. Some patients may experience a prolonged benefit after LVRS not needing a transplant, while in others LVRS may act as a bridge to lung transplantation years later without jeopardising its chances for success [27, 28].

\section{ENDOSCOPIC TECHNIQUES FOR THE MANAGEMENT OF EMPHYSEMA}

Bronchoscopic treatment of emphysema is a new form of minimally invasive therapy pursued by several groups and is

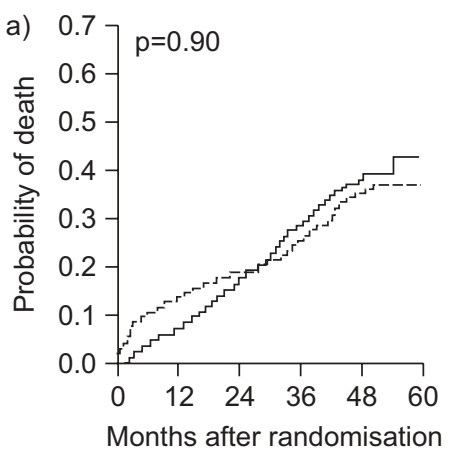

At risk $n$

Surgery Medical therapy $610527 \quad 384224 \quad 70$

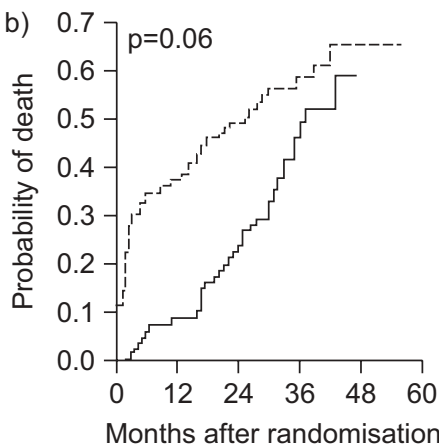

Months after randomisation

$\begin{array}{llllll}\text { At risk n } & & & & & \\ \text { Surgery } & 70 & 44 & 35 & 19 & 4 \\ \text { Medical therapy } & 70 & 64 & 45 & 20 & 0\end{array}$

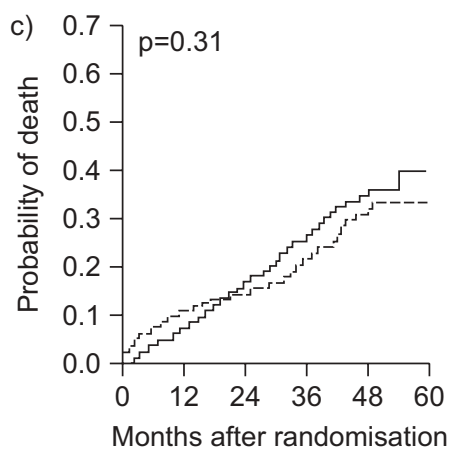

At risk $n$

Surgery

Medical therapy

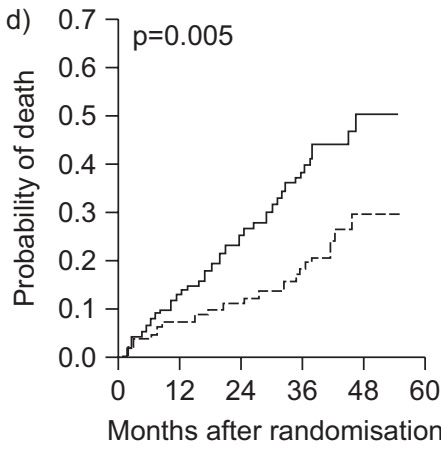

At risk $n$ $\begin{array}{llllll}\text { Surgery } & 139 & 121 & 93 & 61 & 17 \\ \text { Medical therapy } & 151 & 120 & 85 & 43 & 13\end{array}$

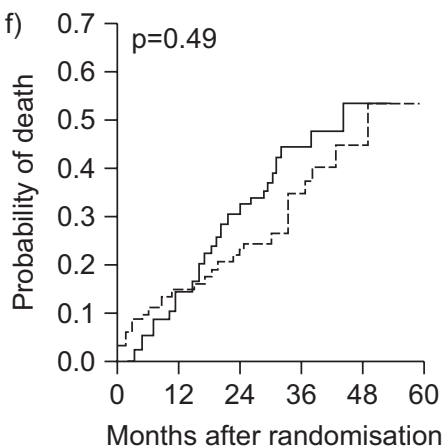

At risk $n$

$\begin{array}{llllll}\text { Surgery } & 84 & 67 & 52 & 28 & 6\end{array}$

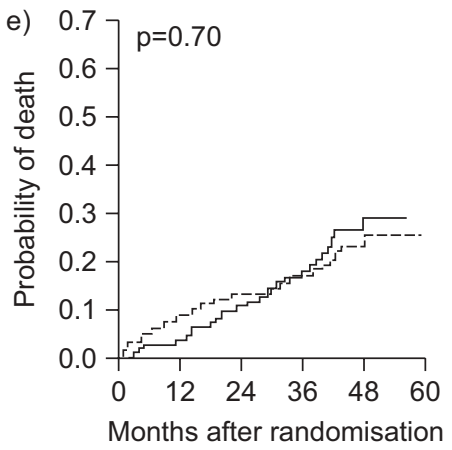

At risk $n$ Surgery $\quad 206 \quad 176 \quad 124 \quad 82 \quad 35$ Medical therapy $213 \quad 192 \quad 149 \quad 104 \quad 35$

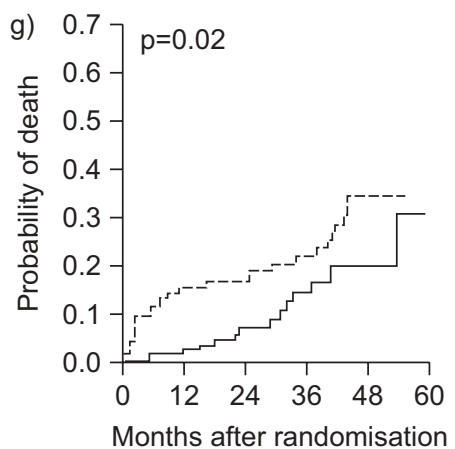

At risk $n$

$\begin{array}{llllll}\text { Surgery } & 109 & 83 & 71 & 43 & 12\end{array}$

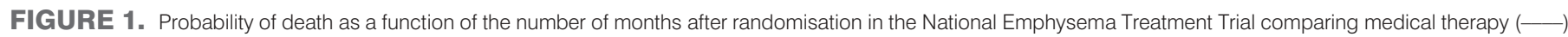

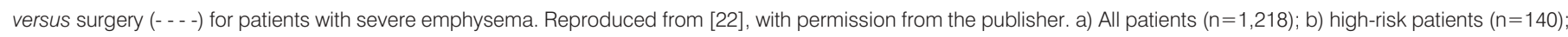

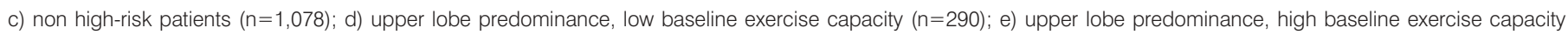
$(n=419)$; $)$ non upper lobe predominance, low baseline exercise capacity $(n=149)$; and g) non upper lobe predominance, high baseline exercise capacity ( $n=220)$. 


\begin{tabular}{|c|c|c|}
\hline TABLE 1 & \multicolumn{2}{|c|}{$\begin{array}{l}\text { Eligibility criteria for lung volume reduction surgery } \\
\text { (LVRS) versus lung transplantation in emphysema } \\
\text { patients }\end{array}$} \\
\hline LVRS & & Lung transplantation \\
\hline \multicolumn{2}{|l|}{ Age $<75$ yrs } & Age $<65$ yrs \\
\hline \multicolumn{2}{|c|}{ FEV $1>20 \%$ to $<45 \%$ pred } & $\mathrm{FEV}_{1}<25 \%$ pred \\
\hline \multicolumn{2}{|c|}{$D\llcorner, \mathrm{CO}>20 \%$ pred } & $D L, C O<20 \%$ pred \\
\hline \multicolumn{2}{|c|}{ RV $>200 \%$ pred } & $\mathrm{Pa}_{\mathrm{a}_{2}}<55 \mathrm{mmHg}$ \\
\hline \multicolumn{2}{|c|}{ 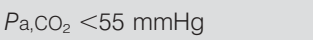 } & $\mathrm{Pa}_{\mathrm{a}, \mathrm{CO}_{2}}>55 \mathrm{mmHg}$ \\
\hline \multicolumn{2}{|c|}{$P$ pa $<45 \mathrm{mmHg}$} & Pulmonary hypertension/cor pulmonale \\
\hline \multicolumn{2}{|c|}{ Heterogeneous emphysema } & All types emphysema including $\alpha_{1}$-ATD \\
\hline \multicolumn{2}{|l|}{ Upper lobe } & Whole lung \\
\hline \multicolumn{2}{|c|}{ Limited exercise capacity } & Limited exercise capacity \\
\hline \multicolumn{3}{|c|}{$\begin{array}{l}\mathrm{FEV} 1 \text {; forced expiratory volume in } 1 \mathrm{~s} \text {; \% pred: \% predicted; } \mathrm{DL}, \mathrm{CO} \text { : diffusion } \\
\text { capacity of the lung for carbon monoxide; RV: residual volume; } \mathrm{Pa}, \mathrm{O}_{2}: \text { arterial } \\
\text { partial oxygen pressure; } \mathrm{Pa}_{\mathrm{a}} \mathrm{CO}_{2}: \text { arterial partial carbon dioxide pressure; } P \text { pa: } \\
\text { pulmonary artery pressure; } \alpha_{1} \text {-ATD: } \alpha_{1} \text {-antitrypsin deficiency. }\end{array}$} \\
\hline
\end{tabular}

currently still undergoing clinical evaluation $[29,30]$. The main potential benefit of these non-surgical approaches is reduced morbidity with possible widening of indications to patients with significant comorbidities or advanced/diffuse diseases that may preclude LVRS. Three concepts for bronchoscopic treatment have emerged, as follows.

The first concept is the placement of one-way valves within the lumen of the airways that only allows air to flow out in the direction of expiration. These valves are targeted at patients with heterogeneous emphysema and have been placed in one or both lungs, in the upper or non-upper lobes, according to the location of the most affected emphysematous regions [30]. Endobronchial obstruction can induce absorption atelectasis with physiological mechanisms of functional improvement that are similar to LVRS but, in most cases, lobar collapse was not observed because of collateral ventilation [31]. Recent studies in limited numbers of patients treated with unilateral valve insertion and reassessed after 4 weeks have shown some benefits in absence of atelectasis that seem to be related to improvement in exercise time associated with increased diffusing capacity and decreased static lung volumes [32]. Two companies are pursuing this area: Spiration, Inc, Redmond, CA, USA with the IBV valves and Emphasys, Inc, Redmond, WA, USA with the second-generation Zephyr valves. The valves are placed through the working channel of a flexible bronchoscope in the segmental and subsegmental airways of the targeted lobe and can be removed bronchoscopically if necessary. Most studies only have short follow-up periods, are open-labelled and have no control arm [33-39]. The initial experience with the Zephyr valve is summarised in the data of a registry report on 98 patients [36]. Unilateral lobar placement was the most frequent approach and statistically significant improvement of pulmonary function (RV, FEV1 and FVC) and exercise tolerance (6-min walk test) was reported. Serious complications included one (1\%) death and seven $(7 \%)$ pneumothoraces or prolonged air leaks; pneumothorax occurred mainly in proximity to an atelectatic lobe. Improvements of greater magnitude were observed in cases with lobar exclusion, unilateral treatment and baseline FEV1 $<30 \%$ [36]. There are only a few studies dealing with the IBV valve treatment of emphysema [37-39]. Patients with severe upper lobe predominant emphysema were selected and bilateral treatment was performed in nearly all cases. In these cases, the lingula was rarely treated, the right middle lobe was not treated with one exception, and atelectasis was observed after treatment in only $9 \%$ (nine out of 98 patients) of the cases [38]. These studies reported significant improvement in healthrelated quality of life but no improvement in exercise, as measured by 6-min walk distance, changes in FEV1 or plethysmographic lung volumes. CT quantitative analysis also showed no change in total lung volume, according to pulmonary function tests results, but there was a significant decrease in upper lobe volumes together with an increase in non-upper lobe volumes [40], and improvement in healthrelated quality of life was associated with a decreased volume in the treated lobes, despite the absence of visible atelectasis [39]. Pneumothorax was the most common adverse event (eight out of 98 patients) and was significantly associated with atelectasis [38].

The results of prospective randomised studies using these endobronchial valves are still awaited [41, 42]. The VENT (endobronchial valve for emphysema palliation) trial has been designed to compare the efficacy and safety of the unilateral lobar treatment of heterogeneous emphysema using Zephyr valve in comparison with best medical treatment, including rehabilitation [41]. Co-primary end-points of this open-label study, namely baseline to 6 months per cent changes in FEV1 $(6.8 \%)$ and 6 -min walk test $(5.8 \%)$ were reached [42], but clinical benefits seemed to be relatively limited. Results of randomised single or double-blind studies using the Spiration valves (ClinicalTrials.gov number NCT00580724 and NCT00475007) in the treatment of bilateral upper lobe predominant severe emphysema are awaited. These latter studies do not target atelectasis (one subsegmental bronchus is left open in the right upper lobe and the lingula is not treated) because of the close association between atelectasis and pneumothorax and have, as composite primary end-point, clinically meaningful improvements in disease-related health status together with regional lung volume changes as measured by quantitative CT scan.

The second concept is that of airway bypass, in which transbronchial fenestrations are created that act as new alternate pathways. Trapped gas is allowed to escape directly from the emphysematous lung taking advantage of collateral ventilation, thereby reducing hyperinflation. The airway bypass is targeted at patients with severe homogeneous emphysema. Experimental studies using explanted emphysematous lungs from transplant recipients have shown that airway bypass results in significantly improved expiratory flow and volume $[43,44]$. Stents were then applied in the lungs of cancer patients undergoing lobectomy and in lungs of emphysematous lung transplant recipients immediately before explantation to demonstrate feasibility and safety of the procedure in humans [45]. Experimental studies continued in a dog model to study the feasibility and safety of the airway bypass stents [46]. Patency was prolonged with the use of paclitaxel-eluting stents [47]. A clinical study using the paclitaxel-eluting airway bypass stents in 35 patients was 
recently published [48]. There were two technical failures and one death from bleeding due to nonadherence to the strict protocol. An average of eight airway holes were created in each patient. Treated patients experienced improvements in pulmonary function parameters RV and FVC. This improvement was more marked in the subset of patients with severe hyperinflation ( $\mathrm{RV} /$ total lung capacity ratio $>0.67)$. A prospective randomised airway bypass study (Exhale Airway Stents for Emphysema; EASE) is presently underway, targeted at patients with homogeneous emphysema.

The third concept is the bronchoscopic instillation of biological adhesives designed to collapse and remodel the hyperinflated lung [49-51] or the delivery of heated water vapour using a disposable bronchoscopic catheter [42, 52]. These treatment modalities act at the alveolar rather than the airway level and are targeted to heterogeneous emphysema [50] and homogeneous emphysema [51]. Furthermore, treatment is intended to produce a permanent change in tissue configuration similar to LVRS rather than reversible adsorption atelectasis. Phase two studies using biological reagents instilled in subsegments have shown that this treatment modality can reduce lung volumes and improve pulmonary function in patients with advanced upper lobe emphysema or homogeneous emphysema with an acceptable side-effect profile [50, 51].

\section{CONCLUSION}

Resectional lung volume reduction has proven to be superior to medical treatment in reducing dyspnoea and in increasing lung function, survival and quality of life in a very well selected, low risk group of hyperinflated patients with heterogeneous emphysema predominantly in the upper lobe. Nevertheless, this intervention is hampered by an important pulmonary $(30 \%)$ and cardiovascular $(20 \%)$ morbidity, mainly as a result of prolonged ( $>7$ days) air leak and a $5 \%$ risk of death from the surgical intervention.

Whether less invasive bronchoscopic techniques using endobronchial valves, airway bypass stents or biological adhesives/ heated water vapour will yield similar improvement, with less morbidity and reduced mortality compared to surgical resection, awaits further results from ongoing randomised trials. More studies are needed to look at patient selection, procedural safety, mechanistic action and short- and longerterm effectiveness of these approaches. Furthermore, it is hoped that endoscopic techniques may help patients with homogeneous emphysema currently excluded by most teams for the resectional procedure.

\section{SUPPORT STATEMENT}

D. Van Raemdonck is a senior clinical investigator supported by the Fund for Research-Flanders (G.3C04.99).

\section{STATEMENT OF INTEREST}

ERS partly reimbursed costs for D. Van Raemdonck's travel to the ERS Congresses in 2007-2009.

\section{REFERENCES}

1 Burrows B, Bloom JW, Traver GA, et al. The course and prognosis of different forms of chronic airways obstruction in a sample from the general population. N Engl J Med 1987; 317: 1309-1314.
2 Celli BR, Cote CG, Marin JM, et al. The body-mass index, airflow obstruction, dyspnea, and exercise capacity index in chronic obstructive pulmonary disease. N Engl J Med 2004; 350: 1005-1012.

3 Deslauriers J. History of surgery for emphysema. Semin Thorac Cardiovasc Surg 1996; 8: 43-51.

4 Brantigan OC, Mueller E. Surgical treatment of pulmonary emphysema. Am Surg 1957; 23: 789-804.

5 Brantigan OC, Mueller E, Kress MB. A surgical approach to pulmonary emphysema. Am Rev Respir Dis 1959; 80: 194-206.

6 Cooper JD, Trulock EP, Triantafillou AN, et al. Bilateral pneumectomy (volume reduction) for chronic obstructive pulmonary disease. J Thorac Cardiovasc Surg 1995; 109: 106-119.

7 Cooper JD, Patterson GA, Sundaresan RS, et al. Results of 150 consecutive bilateral lung volume reduction procedures in patients with severe emphysema. J Thorac Cardiovasc Surg 1996; 112: 1319-1330.

8 Ciccone AM, Meyers BF, Guthrie TJ, et al. Long term outcome of bilateral lung volume reduction in 250 consecutive patients with emphysema. J Thorac Cardiovasc Surg 2003; 125: 513-525.

9 Criner GJ, Cordova FC, Furukawa S, et al. Prospective randomized trial comparing bilateral lung volume reduction surgery to pulmonary rehabilitation in severe chronic obstructive pulmonary disease. Am J Respir Crit Care Med 1999; 160: 2018-2027.

10 Geddes D, Davies M, Koyama H, et al. Effect of lung-volumereduction surgery in patients with severe emphysema. $N$ Engl J Med 2000; 343: 239-245.

11 Pompeo E, Marino M, Nofroni I, et al. Reduction pneumoplasty versus respiratory rehabilitation in severe emphysema: a randomized study. Ann Thorac Surg 2000; 70: 948-954.

12 National Emphysema Treatment Trial Research Group. Safety and efficacy of median sternotomy versus video-assisted thoracic surgery for lung volume reduction surgery. J Thorac Cardiovasc Surg 2004; 127: 1350-1360.

13 Lowdermilk GA, Keenan RJ, Landreneau RJ, et al. Comparison of clinical results for unilateral and bilateral thoracoscopic lung volume reduction. Ann Thorac Surg 2000; 69: 1670-1674.

14 Oey IF, Waller DA, Bal S, et al. Lung volume reduction surgery - a comparison of the long term outcome of unilateral versus bilateral approaches. Eur J Cardiothorac Surg 2002; 22: 610-614.

15 Mineo TC, Pompeo E, Rogliani $\mathrm{P}$, et al. Results of unilateral lung volume reduction surgery in patients with distinct heterogeneity of emphysema between lungs. J Thorac Cardiovasc Surg 2005; 129: 73-79.

16 Meyers BF, Sultan PK, Guthrie TJ, et al. Outcomes after unilateral lung volume reduction. Ann Thorac Surg 2008; 86: 204-212.

17 Hazelrigg SR, Boley TM, Magee MJ, et al. Comparison of staged thoracoscopy and median sternotomy for lung volume reduction. Ann Thorac Surg 1998; 66: 1134-1139.

18 Pompeo E, Mineo TC, for the Pulmonary Emphysema Research Group, Long-term outcome of staged versus one-stage bilateral thoracoscopic reduction pneumoplasty. Eur J Cardiothorac Surg 2002; 21: 627-633.

19 Choong CK, Meyers BF, Battafarano RJ, et al. Lung cancer resection combined with lung volume reduction in patients with severe emphysema. J Thorac Cardiovasc Surg 2004; 127: 1323-1331.

20 National Emphysema Treatment Trial Research Group. Rationale and design of the National Emphysema Treatment Trial (NETT): a prospective randomized trial of lung volume reduction surgery. J Thorac Cardiovasc Surg 1999; 118: 518-528.

21 National Emphysema Treatment Trial Research Group. Patients at high risk of death after lung-volume-reduction surgery. $N$ Engl J Med 2001; 345: 1075-1083.

22 Fishman A, Martinez F, Naunheim K, et al. A randomized trial comparing lung-volume-reduction surgery with medical therapy for severe emphysema. N Engl J Med 2003; 348: 2059-2073.

23 Naunheim K, Wood DE, Mohsenifar Z, et al. Long-term follow up of patients receiving lung-volume-reduction surgery versus medical 
therapy for severe emphysema by the National Emphysema Treatment Trial Research Group. Ann Thorac Surg 2006; 82: 431-443.

24 Naunheim KS, Wood DE, Krasna MJ, et al. Predictors of operative mortality and cardiopulmonary morbidity in the National Emphysema Treatment Trial. J Thorac Cardiovasc Surg 2006; 131 43-53.

25 DeCamp MM, Blackstone EH, Naunheim KS, et al. Patient and surgical factors influencing airleak after lung volume reduction surgery: lessons learned from the National Emphysema Treatment Trial. Ann Thorac Surg 2006; 82: 197-207.

26 Weder W, Tutic M, Lardinois D, et al. Persistent benefit from lung volume reduction surgery in patients with homogeneous emphysema. Ann Thorac Surg 2009; 87: 229-237.

27 Meyers BF, Yusen RD, Guthrie TJ, et al. Outcome of bilateral lung volume reduction surgery in patients with emphysema potentially eligble for lung transplantation. J Thorac Cardiovasc Surg 2001; 122: 10-17.

28 Tutic M, Lardinois D, Imfeld S, et al. Lung-volume reduction surgery as an alternative of bridging procedure to lung transplantation. Ann Thorac Surg 2006; 82: 208-213.

29 Ingenito EP, Wood DE, Utz JP. Bronchoscopic lung volume reduction in severe emphysema. Proc Am Thorac Soc 2008; 5: 454-460.

30 Mamary AJ, Criner GJ. Lung volume reduction surgery and bronchoscopic lung volume reduction in severe emphysema. Respir Med 2008; 4: 44-59.

31 Van Allen CM, Lindskog GE, Richter HG. Collateral respiration: transfer of air collaterally between pulmonary lobules. J Clin Invest 1931; 10: 559-590.

32 Hopkinson NS, Toma TP, Hansell DM, et al. Effect of bronchoscopic lung volume reduction on dynamic hyperinflation and exercise in emphysema. Am J Respir Crit Care Med 2005; 171: 453-460.

33 Toma TP, Hopkinson NS, Hillier J, et al. Bronchoscopic volume reduction with valve implants in patients with severe emphysema. Lancet 2003; 361: 931-933.

34 Snell GI, Holsworth L, Borrill ZL, et al. The potential for bronchoscopic lung volume reduction using bronchial prostheses: a pilot study. Chest 2003; 124: 1073-1080.

35 Venuta F, de Giacomo T, Rendina EA, et al. Bronchoscopic lungvolume reduction with one-way valves in patients with heterogenous emphysema. Ann Thorac Surg 2005; 79: 411-416.

36 Wan IYP, Toma TP, Geddes DM, et al. Bronchoscopic lung volume reduction for endstage emphysema: report on the first 98 patients. Chest 2006; 129: 518-526.

37 Wood DE, McKenna RJ, Yusen RD, et al. A multicenter trial of an intrabronchial valve for treatment of severe emphysema. J Thorac Cardiovasc Surg 2007; 133: 65-73.
38 Springmeyer SC, Boliger CT, Waddell TK, et al. Treatment of heterogeneous emphysema using the spiration valves. Thorac Surg Clin 2009; 19: 247-253.

39 Sterman DH, Mehta AC, Wood DE, et al. A multicenter pilot study of a bronchial valve for the treatment of severe emphysema. Respiration 2010; 79: 222-233.

40 Coxson HO, Fauerbach PVN, Storness-Bliss C, et al. Computed tomography assessment of lung volume changes after bronchial valve treatment. Eur Respir J 2008; 32: 1-8.

41 Strange C, Herth FJ, Kovitz KL, et al. Design of the endobronchial valve for emphysema palliation trial (VENT): a non-surgical method of lung volume reduction. BMC Pulm Med 2007; 7: 10.

42 Herth FJF, Gompelmann D, Ernst A, et al. Endoscopic lung volume reduction. Respiration 2010; 79: 5-13.

43 Choong CK, Macklem PT, Pierce JA, et al. Airway bypass improves the mechanical properties of explanted emphysematous lungs. Am J Respir Crit Care Med 2008; 178: 902-905.

44 Lausberg HF, Chino K, Patterson GA, et al. Bronchial fenestration improves expiratory flow in emphysematous human lungs. Ann Thorac Surg 2003; 75: 393-398.

45 Rendina EA, De Giacomo T, Venuta F, et al. Feasibility and safety of the airway bypass procedure for patients with emphysema. $J$ Thorac Cardiovasc Surg 2003; 125: 1294-1299.

46 Choong CK, Haddad FJ, Gee EY, et al. Feasibility and safety of airway bypass stent placement and influence of topical mitomycin C on stent patency. J Thorac Cardiovasc Surg 2005; 129: 632-638.

47 Choong CK, Phan L, Massetti P, et al. Prolongation of patency of airway bypass stents with use of drug-eluting stents. J Thorac Cardiovasc Surg 2006; 131: 60-64.

48 Cardoso PFG, Snell GI, Hopkins P, et al. Clinical application of airway bypass with paclitaxel-eluting stents: early results. J Thorac Cardiovasc Surg 2007; 134: 974-981.

49 Reilly J, Washko G, Pinto-Plata V, et al. Biological lung volume reduction: a new bronchoscopic therapy for advanced emphysema. Chest 2007; 131: 1108-1113.

50 Criner GJ, Pinto-Plata V, Strange C, et al. Biologic lung volume reduction in advanced upper lobe emphysema: phase 2 results. Am J Respir Crit Care Med 2009; 179: 791-798.

51 Refaely Y, Dransfield M, Kramer MR, et al. Biologic lung volume reduction therapy for advanced homogeneous emphysema. Eur Respir J 2010; [Epub ahead of print DOI 10.1183/09031936. 00106009].

52 Snell GI, Hopkins P, Westall G, et al. A feasibility and safety study of bronchoscopic thermal vapor ablation: a novel emphysema therapy. Ann Thorac Surg 2009; 88: 1993-1998. 